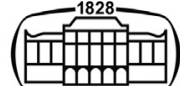

AKADÉMIAI KIADÓ

\title{
The impact of COVID-19 lockdown on gambling habit: A cross-sectional study from Italy
}

\section{Journal of Behavioral Addictions}

$10(2021) 3,711-721$

DOI:

$10.1556 / 2006.2021 .00033$

(c) 2021 The Author(s)

\section{FULL-LENGTH REPORT}

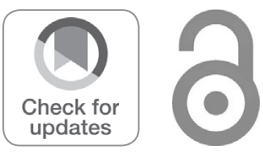

* Corresponding author E-mail: silvano.gallus@marionegri.it

\author{
ALESSANDRA LUGO ${ }^{1}$, CHIARA STIVAL ${ }^{1}$, LUCA PARONI $^{1}$, \\ ANDREA AMERIO ${ }^{2,3}$, GIULIA CARRERAS ${ }^{4}$, \\ GIUSEPPE GORINI ${ }^{4}$, LUISA MASTROBATTISTA ${ }^{5}$, \\ ADELE MINUTILLO ${ }^{5}$, CLAUDIA MORTALI ${ }^{5}$, \\ ANNA ODONE ${ }^{6,7}$, ROBERTA PACIFICI ${ }^{5}$, \\ BIAGIO TINGHINO ${ }^{8}$ and SILVANO GALLUS ${ }^{1 *}$ (1)
}

\footnotetext{
${ }^{1}$ Department of Environmental Health Sciences, Istituto di Ricerche Farmacologiche Mario Negri IRCCS, Milan, Italy

${ }^{2}$ Department of Neuroscience, Rehabilitation, Ophthalmology, Genetics, Maternal and Child Health, Section of Psychiatry, University of Genoa, Genoa, Italy

${ }^{3}$ IRCCS Ospedale Policlinico San Martino, Genoa, Italy

${ }^{4}$ Oncologic Network, Prevention and Research Institute (ISPRO), Florence, Italy

${ }^{5}$ National Centre on Addiction and Doping, Istituto Superiore di Sanità, Rome, Italy

${ }^{6}$ School of Medicine, University Vita-Salute San Raffaele, Milan, Italy

${ }^{7}$ Department of Public Health, Experimental and Forensic Medicine, University of Pavia, Pavia, Italy

${ }^{8}$ UO Alcologia e Nuove Dipendenze, Dipartimento di Salute Mentale e Dipendenze, ASST della Brianza, Vimercate, Italy
}

Received: January 28, 2021 • Revised manuscript received: May 4, 2021 • Accepted: May 15, 2021

Published online: July 20, 2021

\begin{abstract}
Background and aims: Few preliminary studies have shown an impact of COVID-19 confinement on gambling habits. We aim to evaluate short-term effects of lockdown restrictions on gambling behaviors in Italy. Methods: Within the project Lost in Italy, a web-based cross-sectional study was conducted on a representative sample of 6,003 Italians aged 18-74 years, enrolled during April 27May 3 2020, and were asked to report gambling activity before the lockdown and at the time of interview. Results: The prevalence of participants reporting any gambling decreased from $16.3 \%$ before lockdown to $9.7 \%$ during lockdown. Traditional gambling decreased from 9.9 to $2.4 \%$ and online gambling from 9.9 to $8.0 \%$. Among gamblers, median time of gambling grew from 4.5 to $5.1 \mathrm{~h} /$ month. Among non-players before lockdown, 1.1\% started playing. Among players before lockdown, $19.7 \%$ increased gambling activity. Multivariate analysis showed an increase in gambling activity in younger generations ( $\mathrm{p}$ for trend $=0.001$ ), current smokers (odds ratio, OR 1.48), users of electronic cigarettes (OR 1.63), heated tobacco products (OR 1.82), cannabis (OR 5.16), psychotropic drugs (OR 3.93), and subjects having hazardous alcohol drinking (OR 1.93). Self-reported low quality of life (OR 1.97), low sleep quantity (OR 2.00), depressive symptoms (OR 3.06) and anxiety symptoms (OR 2.93) were significantly related to an increase in total gambling activity during lockdown. Discussion and conclusions: Although gambling substantially decreased during lockdown, time spent in gambling slightly increased. The strong relationship found between compromised mental health and addictive behaviors calls for urgent policies to prevent vulnerable populations from increasing and developing severe gambling addiction.
\end{abstract}

\section{KEYWORDS}

gambling, poly-addiction, mental health, COVID-19, lockdown, Italy 


\section{INTRODUCTION}

Gambling is defined as an activity which involves placing money or valuable goods at stake, with the hope of gaining a greater amount of money or goods with a greater value (Potenza, Kosten, \& Rounsaville, 2001; World Health Organization, 2017). Gambling has existed for a long time, and since the mid-1980s there has been unprecedented growth in commercial gambling, with annual global losses due to gambling estimated to be $\$ 400$ billion in 2016 (Bogart, 2011; The data team, 2017). Today, gambling can be experienced in several forms, either table-based, electronic-based or sports-based (Potenza et al., 2019). Gambling can be both land-based (traditional gambling) or over the internet (online gambling) (Elton-Marshall, Leatherdale, \& Turner, 2016).

Despite gambling is widely recognized as a popular leisure activity, it can affect well-being, social interactions and financial status of selected individuals. Gambling might therefore represent a potential public health concerning activity (Latvala, Lintonen, \& Konu, 2019). Lifetime prevalence of combined problem gambling and pathological gambling has been estimated to range from 0.7 to $6.5 \%$ worldwide (Calado \& Griffiths, 2016) and from 0.5 to $3.8 \%$ in Italy (Cavalera et al., 2018).

Italy was among the first European countries to report a case of SARS-CoV-2 infection on January 23, 2020, after the outbreak of the virus in Wuhan region of China (Saglietto, D'Ascenzo, Zoccai, \& De Ferrari, 2020). The Italian Government introduced first health protection measures on January 25, but new, more restrictive measures were introduced shortly afterwards (Signorelli, Scognamiglio, \& Odone, 2020). To face the new epidemic emergency, on March 9, 2020 limitations were placed on individual freedom to move and only strictly indispensable activities were allowed in the entire country (Presidenza del Consiglio dei Ministri, 2020). National-level stay-at-home order ended on May 4, 2020, after almost two months. Among the Government restriction measures, most land-based gambling activities were banned from March 12 towards June 12, 2020 (Agenzie Dogane Monopoli, 2020).

Although a reduction in gambling activity is therefore expected during the COVID-19 pandemic, it is also possible that the COVID-19 crisis impacted the financial and psychological well-being and the corresponding forced lockdown caused an important increase of time spent at home with an enhanced engagement in addictive behaviors, including online gaming and pornography-viewing (King, Delfabbro, Billieux, \& Potenza, 2020), tobacco smoking (Carreras et al., 2021) and alcohol drinking. In this scenario also online gambling intensity might have increased during the confinement period. Some authors and experts suggested that the crisis caused by COVID-19 could have effects on gambling behaviors too: boredom, stress, financial concerns, anxiety, depression, negative thinking and loneliness have all a well-established link with gambling disorders and some of the protective factors that offer stability and reduce harm have been removed, including regular routine and structured daily activity (Yahya \& Khawaja, 2020).

So far, only few preliminary cross-sectional studies, based on convenience samples (i.e., non-representative of the national adult populations), have investigated the impact of the global COVID-19 pandemic on gambling (Mallet, Dubertret, \& Le Strat, 2020). In general, those studies, based on relatively limited sample sizes, showed a large impact of COVID-19 confinement on gambling habits. A higher proportion of gamblers decreasing rather than increasing their gambling habit was consistently observed during the COVID-19 crisis, in countries with (Australian Institute of Criminology, 2020; The University of Sidney, 2020) and without national restriction in gambling (Hakansson, 2020).

In Italy, gambling habits have been recently investigated. A report by the Italian National Institute of Health showed that more than one third (i.e., 36\%) of the adult population gambles at least once a year (Pacifici, Mastrobattista, Minutillo, \& Mortali, 2019). Moreover, a cross-sectional study, based on 4,773 Italian adults from the Lombardy region, showed a relatively limited prevalence of problematic gamblers (Cavalera et al., 2018).

Given the limited information from Italy on gambling habits in the context of the COVID-19 lockdown, we conducted a cross-sectional study on a large representative sample of Italian adults, during the first phase of the COVID-19 lockdown, with the aim of evaluating short-term impact of lockdown restrictions on gambling habits of Italian adults and the corresponding potential determinants (Odone et al., 2020).

\section{METHODS}

Within the project LOckdown and lifeSTyles IN ITALY (Lost in Italy), a web-based cross-sectional study was conducted between April 27th and May 3rd 2020 (i.e., within the hardest phase of the COVID-19 lockdown) on a large representative sample of adults aged 18-74 years (approximately $72.6 \%$ of the Italian population), including an oversample of subjects coming from Lombardy region, the Italian region most affected by coronavirus outbreak. The survey was carried out by DOXA, the Italian branch of the Worldwide Independent Network/Gallup International Association, in collaboration with the Italian National Institute of Health and the Mario Negri Institute for Pharmacological Research.

Participants were recruited from panellists of the DOXA online panel including more than 140,000 Italian adults. The DOXA online panel is an initiative exclusively dedicated to research and is built to reflect the "general public"; including profiles as diverse as possible. Using a quota sampling method by age, sex and region (the first-level constituent Italian entity), we randomly selected, from all the 140,000 panellists, 6,003 participants (2,962 men and 3,041 women). This allowed us to obtain an accurate representation of the general Italian adult population. 
Recruited subjects filled out an online self-administered questionnaire, including information on demographic and socio-economic characteristics, such as level of education and geographic area. We also collected information on addictive behaviors and mental health symptoms prior and during COVID-19 lockdown (i.e., end of April). Requested addictive behaviors included smoking status, use of electronic cigarette, heated tobacco products (HTP), cannabis, and alcohol use disorder according to AUDIT-C scale (Saunders, Aasland, Babor, de la Fuente, \& Grant, 1993). Mental health indicators included self-reported quality of life (through a 1-10 visual analogue scale, VAS; low quality of life: VAS 55) (Robinson, Loomes, \& Jones-Lee, 2001), quality and quantity of sleep (2 items of the Pittsburgh Sleep Quality Index, PSQI; low sleep quality: quite bad and very bad sleep quality; low sleep quantity: $<7 \mathrm{~h}$ of sleep per night) (Buysse, Reynolds, Monk, Berman, \& Kupfer, 1989), anxiety levels (Generalized anxiety disorder scale, GAD-2; presence of anxiety symptoms: GAD-2 $\geq 3$ ) (Spitzer, Kroenke, \& Williams, 1999), and depressive symptoms (patient heath questionnaire, PHQ-2; presence of depressive symptoms: PHQ-2 $\geq 3$ ) (Kroenke, Spitzer, \& Williams, 2003).

A specific section of the survey questionnaire was focused on gambling habit. Participants were asked about gambling habit and type of gambling: exclusively "traditional gambling" (i.e., played any game which is not online and requires the person to physically go to a place to gamble), exclusively "online gambling" (on specific gambling websites) or "both traditional and online gambling"; Subjects were classified as gamblers if they answered positively the above questions (Pacifici et al., 2019). Participants were also asked about: i) selected games played among traditional (i.e., slot machines, video lottery terminal-VLT, national lotteries, scratch-off, bingo, lotto, deferred outcome lottery, numerical games, sport betting, casino and virtual betting) and online games (i.e., slot machines, national lotteries, scratch-off, bingo, deferred outcome lottery, numerical games, sport betting, poker, casino and virtual betting); ii) for each game, the frequency of days spent playing (i.e., once per month, 2-3 per month, 1-2 per week, 3-4 per week, 5-6 per week, every day), and iii) the relative time per day spent playing (i.e., <30 min per day, 30-60 $\mathrm{min}, 1-2,2-3,3 \mathrm{~h}$ or more per day).

In order to quantify the impact of COVID-19 lockdown on gambling habit, all the questions on gambling were asked both before (within the four weeks preceding the COVID-19 lockdown - reference time: early February 2020) and during the lockdown (within four weeks before the time of filling out the questionnaire - reference time: April 2020).

For each participant and each specific game, we calculated the hours per month spent playing. We multiplied the game-specific monthly frequency with the relative daily time played. We summed all the game-specific hours per month spent playing in order to derive the total gambling activity (hours per month) before and during the COVID-19 lockdown.
In order to identify the changes in gambling habit during lockdown compared to before lockdown we defined if the subjects had a worsening or an improvement in their gambling habits: i) we defined a worsening in gambling behavior if a person was not a gambler before the lockdown and started gambling during the lockdown, or if he/she was already a gambler before the lockdown and reported any increase in the hours per month devoted to gambling; ii) we defined an improvement in gambling behavior if a person was a gambler before the lockdown and stopped gambling during the lockdown, or if he/she was a gambler before lockdown and reported any decrease in the hours per month dedicated to gambling.

\section{Statistical analysis}

We considered descriptive statistics including relative frequency (\%) and its corresponding 95\% confidence intervals (CIs) for categorical variables, and median and interquartile range (IQR) for continuous variables. Differences between medians were tested through the sign test. Multiple logistic regression models after adjustment for sex, age group, level of education, and geographic area were used to derive odds ratios (OR), and corresponding 95\% CIs for: i) gamblers vs. nongamblers before lockdown among the overall population, ii) individuals who started vs. those who did not start playing gambling among non-players before lockdown (worsening gambling habit); iii) individuals who increased vs. those who did not increase their total gambling activity among players before lockdown (worsening gambling habit). Multinomial logistic regression models after adjustment for the same covariates were used to derive ORs for: i) individuals who quit playing and ii) individuals who decreased total gambling activity, both compared to those who did not improve their gambling habit, among players before lockdown. For all the analyses, the independent variables (potential determinants), including the addictive behaviors and mental health indicators, referred to the period prior the lockdown (i.e., early February).

In sensitivity analyses, we considered a different definition of worsening and improvement of gambling activity: instead of considering them as any increase or decrease in the amount of hours dedicated to gambling, we defined as worsening an increase of more than $25 \%$, and as improvement a reduction of more than $25 \%$, of the total gambling activity compared to the period before lockdown.

A statistical weight was applied to all the analyses to guarantee the representativeness of the national sample in terms of sex, age, socio-economic status, and geographic area. All statistical analyses were performed using SAS 9.4 (Cary, North Carolina, USA). These analyses were not preregistered on a publicly available platform, thus results should be considered exploratory.

\section{Ethics}

The protocol of the study was approved by the ethics committee (EC) of the coordinating group (EC of Fondazione IRCCS Istituto Neurologico Carlo Besta, File number 71-73, April 2020). All the participants provided their consent to participate in the study. 


\section{RESULTS}

Among 6,003 Italian adults, 980 (16.3\%; 95\% CI: 15.4$17.3 \%)$ reported to play any type of gambling during prelockdown period and 583 (9.7\%; 95\% CI: 9.0-10.5\%) during lockdown. Figure 1 and Table S1 show the distribution of the Italian adult population according to type of gambling habit, overall and by sex, age and geographic area. Traditional gambling prevalence decreased from 9.9\% (95\% CI: $9.1-10.6 \%$ ) in pre-lockdown to $2.4 \%$ (95\% CI: $2.1-2.8 \%$ ) during lockdown. Online gambling prevalence decreased from $9.9 \%$ (95\% CI: $9.2-10.7 \%$ ) in pre-lockdown to $8.0 \%$ (95\% CI: 7.3-8.7\%) during lockdown.

Overall, the proportion of Italian adults reporting to play gambling $10 \mathrm{~h} / \mathrm{month}$ or more, decreased from $4.9 \%$, before lockdown to $3.8 \%$ during lockdown (data not shown in tables).

Figure 2 shows gambling pre- and during lockdown, overall and according to specific games. In general, traditional gambling showed an overall change by $-76 \%$, from other casino games $(-54 \%)$ to traditional lottery $(-100 \%)$. Online gambling showed an overall change by $-20 \%$, from sport betting $(-59 \%)$ to virtual betting $(+8 \%)$.

Out of the total sample, $4,967(82.7 \%)$ subjects never played gambling both in pre and during-lockdown and 1,036 subjects (17.3\%) played gambling either in pre or during lockdown (ever gamblers). Among ever gamblers, 453 (43.7\%) quit playing during lockdown, 56 (5.4\%) started playing during lockdown and 527 (50.9\%) gambled both in pre and during lockdown. Among gamblers, the median time of gambling activity grew from $4.5 \mathrm{~h}$ per month before the lockdown (IQR: 1.5-13.0) to $5.1 \mathrm{~h}$ per month (IQR: $1.5-$
20.0) during lockdown $(P$ value $<0.001)$. Taking into account both prevalence and intensity of gambling, the overall gambling activity decreased by $29 \%$ compared to the period before the lockdown, mainly in women $(17 \%$ in men and $49 \%$ in women) and in older age (35\% in age class $18-34$, $16 \%$ in $35-54$ and $41 \%$ in $55-74)$.

The 980 subjects reporting to be players before lockdown were more frequently men (OR 2.68; 95\% CI: 2.32-3.11) and people coming from Southern Italy (compared to those from Northern Italy, OR 1.26; 95\% CI: 1.07-1.47). An inverse relationship was observed between gambling and age ( $\mathrm{p}$ for trend $<0.001$ ) (Table 1).

On the total sample, 249 (4.1\%) reported a worsening in their gambling habit during lockdown. In particular, among players before lockdown, 193 (19.7\%) reported an increase in their total gambling activity during lockdown; among the 5,023 non-players before lockdown, $56(1.1 \%)$ started playing during lockdown. In general, a worsening in gambling habit was observed more frequently with decreasing age ( $p$ for trend $=0.001$ for increasing intensity, $\mathrm{p}$ for trend $=$ 0.003 for starting playing).

Gambling before lockdown was more frequently reported among ever smokers (compared to never smokers, OR 1.34; 95\% CI: $1.04-1.73$ for former and OR 2.50; 95\% CI 2.14-2.92 for current smokers), electronic cigarette ever users (OR 1.77; 95\% CI: 1.52-2.07), HTP ever users (OR 2.08; 95\% CI: 1.72-2.53), subjects at alcohol risk (OR 2.51; 95\% CI: 2.17-2.91) and cannabis users (OR 6.15; 95\% CI: 4.96-7.63; Table 2). An increase in the intensity of gambling was more frequently reported in current smokers (compared to never smokers, OR 1.48; 95\% CI: 1.06-2.08), in electronic cigarettes ever users (OR 1.63; 95\% CI: 1.17-2.27), in HTP

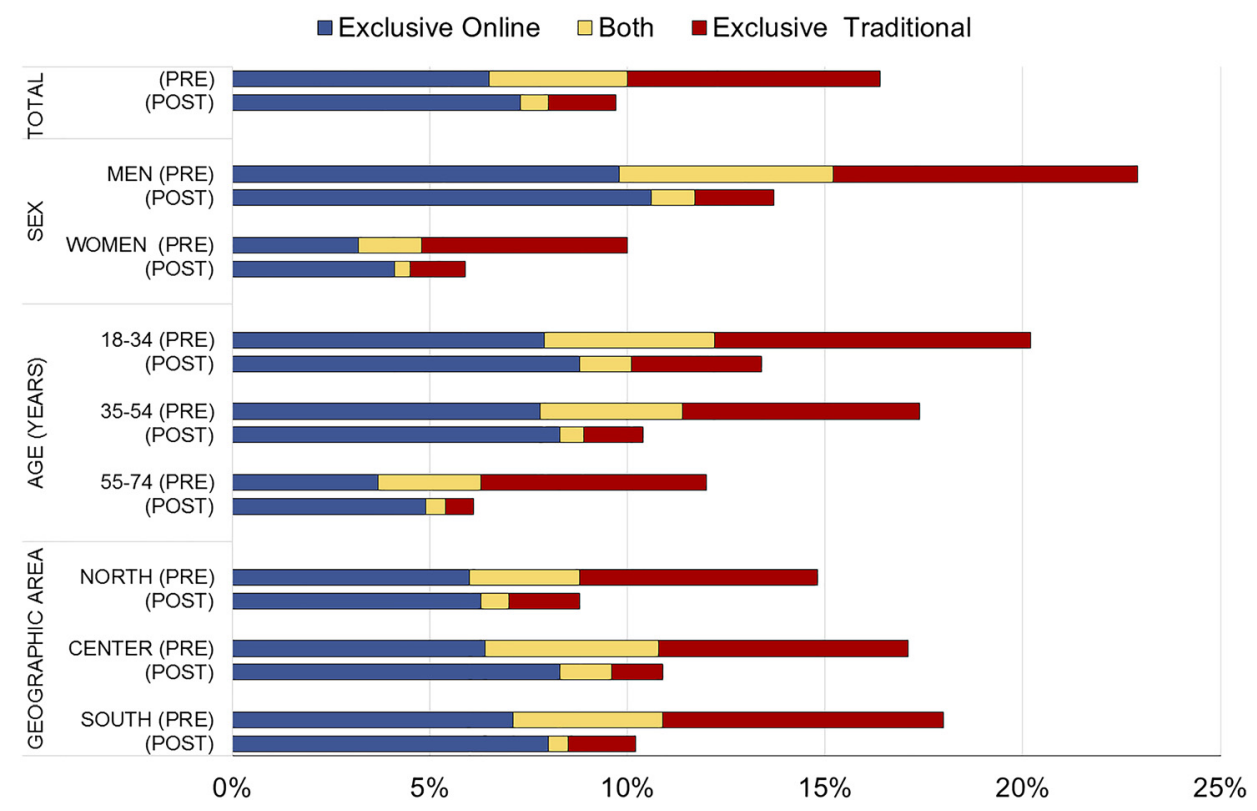

Fig. 1. Distribution of gambling habit before and during COVID-19 lockdown in 6,003 Italian adults, by type of gambling (traditional, online or both) and according to sex, age and geographic area. Italy 2020.

PRE = pre-lockdown (reference time: early February 2020); POST = during-lockdown (reference time: within four weeks before the time of filling out the questionnaire); NORTH = North of Italy; CENTER = Center of Italy; SOUTH = South of Italy and Italian Islands 


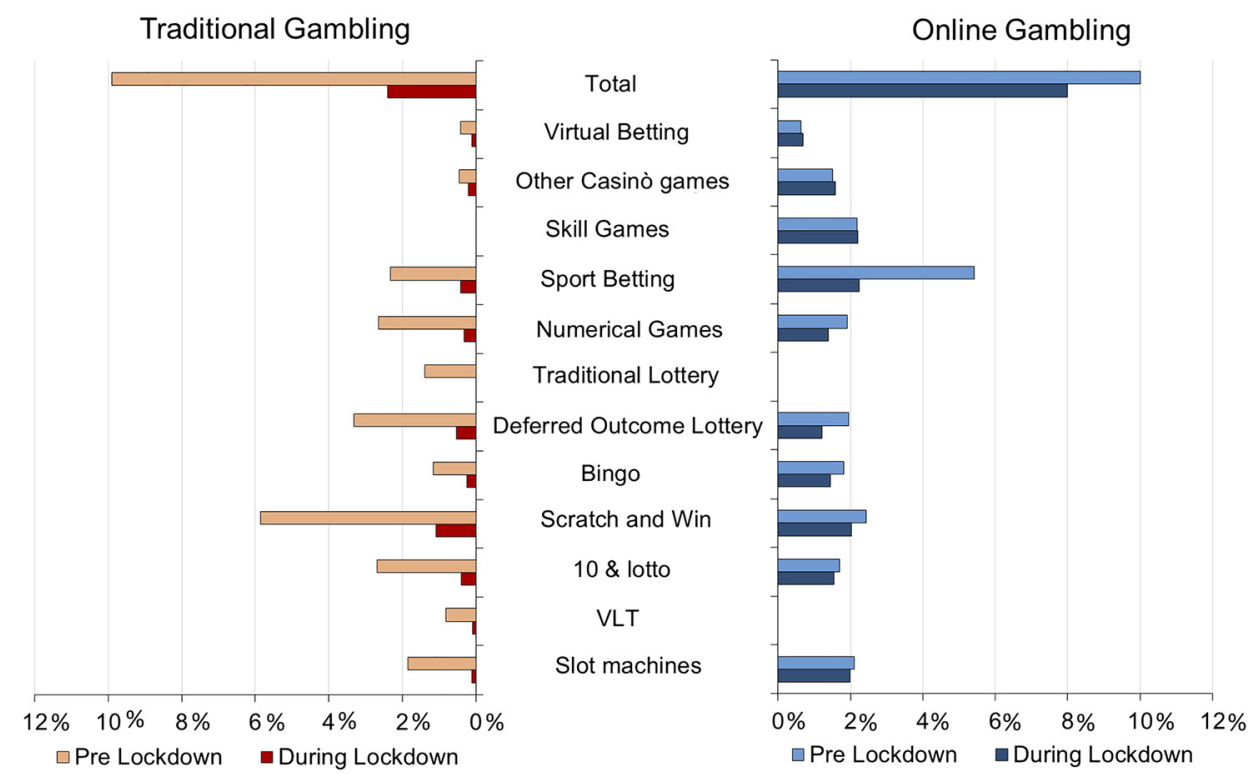

Fig. 2. Percent use (\%) of gambling by specific game among the 6,003 Italians before and during the COVID-19 lockdown. Italy, 2020. VLT $=$ Video Lottery Terminal; pre-lockdown (reference time: early February 2020); during-lockdown (reference time: within four weeks before the time of filling out the questionnaire)

Table 1. Distribution of 6,003 Italians according to their gambling habit and according to a worsening in total gambling activity (i.e., start playing for non-players or increase playing for players) during COVID-19 lockdown, overall and by socio-demographic characteristics. Corresponding odds ratios $^{\circ}(\mathrm{OR})$ and $95 \%$ confidence intervals (CI). Italy, 2020

\begin{tabular}{|c|c|c|c|c|c|c|c|c|c|}
\hline \multirow[b]{3}{*}{ Characteristics before lockdown } & \multicolumn{3}{|c|}{ Overall population } & \multicolumn{3}{|c|}{$\begin{array}{l}\text { Gambling non-players before } \\
\text { lockdown }\end{array}$} & \multicolumn{3}{|c|}{$\begin{array}{l}\text { Gambling players before } \\
\text { lockdown }\end{array}$} \\
\hline & \multirow[b]{2}{*}{$N$} & \multicolumn{2}{|c|}{$\begin{array}{c}\text { Gambling before } \\
\text { lockdown }\end{array}$} & \multirow[b]{2}{*}{$N$} & \multicolumn{2}{|c|}{$\begin{array}{l}\text { Starting gambling } \\
\text { during lockdown }\end{array}$} & \multirow[b]{2}{*}{$N$} & \multicolumn{2}{|c|}{$\begin{array}{c}\text { Increasing intensity of } \\
\text { gambling during } \\
\text { lockdown }\end{array}$} \\
\hline & & $\%$ & OR $(95 \% \mathrm{CI})$ & & $\%$ & OR $(95 \% \mathrm{CI})$ & & $\%$ & OR $(95 \% \mathrm{CI})$ \\
\hline Total & 6,003 & 16.3 & & 5,023 & 1.1 & & 980 & 19.7 & \\
\hline \multicolumn{10}{|l|}{ Sex } \\
\hline Women & 3,041 & 10.0 & $1.00^{\wedge}$ & 2,737 & 0.9 & $1.00^{\wedge}$ & 303 & 18.6 & $1.00^{\wedge}$ \\
\hline Men & 2,962 & 22.9 & $2.68(2.32-3.11)$ & 2,285 & 1.3 & $1.45(0.85-2.47)$ & 677 & 20.2 & $1.00(0.70-1.43)$ \\
\hline \multicolumn{10}{|l|}{ Age group } \\
\hline $18-34$ & 1,557 & 20.2 & $1.00^{\wedge}$ & 1,242 & 1.5 & $1.00^{\wedge}$ & 314 & 25.5 & $1.00^{\wedge}$ \\
\hline $35-54$ & 2,457 & 17.4 & $0.84(0.71-0.99)$ & 2,031 & 1.5 & $1.01(0.56-1.82)$ & 427 & 18.5 & $0.67(0.47-0.95)$ \\
\hline $55-74$ & 1,989 & 12.0 & $0.55(0.45-0.66)$ & 1,749 & 0.4 & $0.27(0.11-0.65)$ & 239 & 14.3 & $0.49(0.31-0.76)$ \\
\hline P for trend & & & $<0.001$ & & & 0.003 & & & 0.001 \\
\hline \multicolumn{10}{|l|}{ Level of education } \\
\hline Low & 911 & 16.0 & $1.00^{\wedge}$ & 765 & 1.1 & $1.00^{\wedge}$ & 146 & 17.1 & $1.00^{\wedge}$ \\
\hline Intermediate & 3,032 & 16.3 & $1.09(0.89-1.34)$ & 2,539 & 1.0 & $0.90(0.41-1.98)$ & 494 & 19.4 & $1.16(0.71-1.90)$ \\
\hline High & 2,060 & 16.6 & $1.04(0.84-1.30)$ & 1,719 & 1.2 & $1.02(0.46-2.28)$ & 341 & 21.2 & $1.26(0.76-2.11)$ \\
\hline $\mathrm{P}$ for trend & & & 0.877 & & & 0.861 & & & 0.371 \\
\hline \multicolumn{10}{|l|}{ Geographic area } \\
\hline Northern Italy & 2,764 & 14.9 & $1.00^{\wedge}$ & 2,354 & 1.2 & $1.00^{\wedge}$ & 411 & 18.5 & $1.00^{\wedge}$ \\
\hline Central Italy & 1,201 & 17.1 & $1.20(0.99-1.45)$ & 996 & 0.9 & $0.74(0.34-1.61)$ & 205 & 24.7 & $1.45(0.97-2.19)$ \\
\hline Southern Italy \& Islands & 2,037 & 17.9 & $1.26(1.07-1.47)$ & 1,673 & 1.2 & $1.01(0.56-1.81)$ & 365 & 18.3 & $0.97(0.67-1.40)$ \\
\hline
\end{tabular}

${ }^{\circ}$ Estimated by unconditional multiple logistic regression models after adjustment for sex, age, education level and geographic area; estimates in bold are those statistically significant at 0.05 level.

$\wedge$ Reference category.

ever users (OR 1.82; 95\% CI: 1.25-2.64), in cannabis users (OR 5.16; 95\% CI: 3.56-7.46) and subjects at alcohol risk (OR 1.93; 95\% CI: 1.39-2.66). No statistically significant differences were observed in the relationship between addictive behaviors and a start in gambling, except for cannabis users (OR 2.99; 95\% CI: 1.33-6.73). 
Table 2. Distribution of 6,003 Italians according to their gambling habit and according to a worsening in total gambling activity (i.e., start playing for non-players or increase playing for players) during COVID-19 lockdown, overall and by addictive behaviors. Corresponding odds ratios ${ }^{\circ}(\mathrm{OR})$ and $95 \%$ confidence intervals (CI). Italy, 2020

\begin{tabular}{|c|c|c|c|c|c|c|c|c|c|}
\hline \multirow[b]{3}{*}{ Characteristics before lockdown } & \multicolumn{3}{|c|}{ Overall population } & \multicolumn{3}{|c|}{$\begin{array}{c}\text { Gambling non-players before } \\
\text { lockdown }\end{array}$} & \multicolumn{3}{|c|}{$\begin{array}{l}\text { Gambling players before } \\
\text { lockdown }\end{array}$} \\
\hline & \multirow[b]{2}{*}{$N$} & \multicolumn{2}{|c|}{$\begin{array}{l}\text { Gambling before } \\
\text { lockdown }\end{array}$} & \multirow[b]{2}{*}{$N$} & \multicolumn{2}{|c|}{$\begin{array}{l}\text { Starting playing } \\
\text { during lockdown }\end{array}$} & \multirow[b]{2}{*}{$N$} & \multicolumn{2}{|c|}{$\begin{array}{c}\text { Increasing intensity of } \\
\text { gambling during } \\
\text { lockdown }\end{array}$} \\
\hline & & $\%$ & OR $(95 \% \mathrm{CI})$ & & $\%$ & OR $(95 \% \mathrm{CI})$ & & $\%$ & OR $(95 \% \mathrm{CI})$ \\
\hline Total & 6,003 & 16.3 & & 5,023 & 1.1 & & 980 & 19.7 & \\
\hline \multicolumn{10}{|l|}{ Smoking status } \\
\hline Never & 4,053 & 12.9 & $1.00^{\wedge}$ & 3,529 & 1.2 & $1.00^{\wedge}$ & 524 & 17.5 & $1.00^{\wedge}$ \\
\hline Former & 549 & 15.8 & $1.34(1.04-1.73)$ & 463 & 0.5 & $0.50(0.13-1.96)$ & 87 & 19.7 & $1.29(0.72-2.32)$ \\
\hline Current & 1,400 & 26.4 & $2.50(2.14-2.92)$ & 1,031 & 1.0 & $0.82(0.41-1.64)$ & 369 & 22.8 & $1.48(1.06-2.08)$ \\
\hline \multicolumn{10}{|l|}{ Electronic cigarette use } \\
\hline Never & 4,676 & 14.3 & $1.00^{\wedge}$ & 4,006 & 1.1 & $1.00^{\wedge}$ & 671 & 16.9 & $1.00^{\wedge}$ \\
\hline Past & 840 & 23.7 & $1.80(1.49-2.16)$ & 641 & 1.6 & $1.48(0.74-2.94)$ & 199 & 26.4 & $1.67(1.14-2.45)$ \\
\hline Current & 487 & 22.7 & $1.74(1.38-2.20)$ & 376 & 0.7 & $0.69(0.20-2.33)$ & 111 & 24.8 & $1.56(0.96-2.52)$ \\
\hline \multicolumn{10}{|l|}{ HTP use } \\
\hline Never & 5,341 & 14.9 & $1.00^{\wedge}$ & 4,544 & 1.1 & $1.00^{\wedge}$ & 797 & 17.4 & $1.00^{\wedge}$ \\
\hline Past & 422 & 28.1 & $2.12(1.68-2.68)$ & 303 & 0.9 & $0.68(0.20-2.38)$ & 119 & 31.6 & $1.99(1.29-3.07)$ \\
\hline Current & 240 & 26.9 & $2.02(1.49-2.73)$ & 176 & 0.7 & $0.55(0.09-3.36)$ & 65 & 25.7 & $1.53(0.84-2.77)$ \\
\hline \multicolumn{10}{|l|}{ Alcohol (AUDIT-C) } \\
\hline Not at risk & 4,417 & 12.7 & $1.00^{\wedge}$ & 3,854 & 1.0 & $1.00^{\wedge}$ & 562 & 15.2 & $1.00^{\wedge}$ \\
\hline At risk & 1,586 & 26.4 & $2.51(2.17-2.91)$ & 1,168 & 1.5 & $1.52(0.86-2.69)$ & 418 & 25.7 & $1.93(1.39-2.66)$ \\
\hline \multicolumn{10}{|l|}{ Cannabis use } \\
\hline No & 5,582 & 13.7 & $1.00^{\wedge}$ & 4,818 & 1.0 & $1.00^{\wedge}$ & 764 & 13.2 & $1.00^{\wedge}$ \\
\hline Yes & 421 & 51.4 & $6.15(4.96-7.63)$ & 205 & 3.4 & $2.99(1.33-6.73)$ & 216 & 42.7 & $5.16(3.56-7.46)$ \\
\hline
\end{tabular}

AUDIT-C: alcohol use disorders identification test; HTP: heated tobacco products.

${ }^{\circ}$ Estimated by unconditional multiple logistic regression models after adjustment for sex, age, education level and geographic area; estimates in bold are those statistically significant at 0.05 level.

$\wedge$ Reference category.

When focusing on mental health indicators before the lockdown (Table 3), gambling before lockdown was more frequently reported in those using psychotropic drugs (OR 3.12; 95\% CI: 2.56-3.81), reporting a low quality of life (OR 1.61 ; $95 \%$ CI: $1.33-1.95$ ), a low sleep quality (OR 1.32; $95 \%$ CI: $1.11-1.58$ ), depressive symptoms (OR 1.82; $95 \%$ CI: $1.52-2.18$ ) and anxiety symptoms (OR 1.87 ; $95 \%$ CI: $1.58-$ 2.22). The use of psychotropic drugs was related to a start and an increase in gambling habit (OR 3.33; 95\% CI: 1.676.65 and OR $3.93 ; 95 \%$ CI: $2.74-5.63$, respectively). Reporting a low quality of life (OR 1.97; CI: 1.34-2.88), low sleep quantity (OR 2.00; 95\% CI: 1.45-2.77), depressive symptoms (OR 3.06; 95\% CI: 2.13-4.39) and anxiety symptoms (OR 2.93; 95\% CI: 2.08-4.13) were related to an increase in the total gambling activity among gamblers before lockdown.

Of the overall 980 players before lockdown, 703 (71.7\%) reported to have experienced an improvement in total gambling activity during lockdown (Table 4). In particular, $453(46.2 \%)$ stopped playing and $250(25.5 \%)$ reduced the intensity of gambling. A stop in gambling was observed more frequently with increasing age $(\mathrm{p}$ for trend $=0.001$ ) and less frequently in people from Central Italy (compared to Northern Italy, OR $0.60 ; 95 \%$ CI $0.41-0.89$ ). Considering addictive behaviors and mental health indicators, we obtained complementary results with those found for the worsening in total gambling activity (Table S2 and S3).

Sensitivity analyses, considering the different definition of worsening and improvement of gambling behaviors (i.e., increase and decrease of more than $25 \%$ the time spent gambling compared to before lockdown), showed comparable results (Tables S4-S9).

\section{DISCUSSION}

Our national survey, based on a large, representative sample of Italian adults, found that the prevalence of gambling habit decreased during COVID-19 lockdown in Italy, while, among gamblers, the intensity of gambling significantly increased in the same time period, leading to an overall decrease in gambling activity (considering both prevalence and intensity) by $29 \%$. In particular, the national regulation banning many types of land-based games resulted in a fall by $76 \%$ of the prevalence of traditional gambling. Even online gamblers declined by $20 \%$ during lockdown, but a non-negligible portion of Italian adults (i.e., 4\%) reported a worsening in their total gambling activity during lockdown (e.g., an increase in intensity or a start of the habit). 
Table 3. Distribution of 6,003 Italians according to their gambling habit and according to a worsening in total gambling activity (i.e., start playing for non-players or increase playing for players) during COVID-19 lockdown, overall and by mental health indicators. Corresponding odds ratios $^{\circ}(\mathrm{OR})$ and 95\% confidence intervals (CI). Italy, 2020

\begin{tabular}{|c|c|c|c|c|c|c|c|c|c|}
\hline \multirow[b]{3}{*}{ Characteristics before lockdown } & \multirow[b]{3}{*}{$N$} & \multicolumn{2}{|c|}{ Overall population } & \multicolumn{3}{|c|}{$\begin{array}{c}\text { Gambling non-players before } \\
\text { lockdown }\end{array}$} & \multicolumn{3}{|c|}{$\begin{array}{l}\text { Gambling players before } \\
\text { lockdown }\end{array}$} \\
\hline & & \multicolumn{2}{|c|}{$\begin{array}{l}\text { Gambling before } \\
\text { lockdown }\end{array}$} & \multirow[b]{2}{*}{$N$} & \multicolumn{2}{|c|}{$\begin{array}{l}\text { Starting playing } \\
\text { during lockdown }\end{array}$} & \multirow[b]{2}{*}{$N$} & \multicolumn{2}{|c|}{$\begin{array}{c}\text { Increasing intensity of } \\
\text { gambling during } \\
\text { lockdown }\end{array}$} \\
\hline & & $\%$ & OR $(95 \% \mathrm{CI})$ & & $\%$ & OR $(95 \% \mathrm{CI})$ & & $\%$ & OR $(95 \% \mathrm{CI})$ \\
\hline Total & 6,003 & 16.3 & & 5,023 & 1.1 & & 980 & 19.7 & \\
\hline \multicolumn{10}{|l|}{ Psychotropic drugs } \\
\hline No & 5,432 & 14.6 & $1.00^{\wedge}$ & 4,641 & 1.0 & $1.00^{\wedge}$ & 791 & 14.6 & $1.00^{\wedge}$ \\
\hline Yes & 571 & 33.2 & $3.12(2.56-3.81)$ & 381 & 2.7 & $3.33(1.67-6.65)$ & 189 & 41.2 & $3.93(2.74-5.63)$ \\
\hline \multicolumn{10}{|l|}{ Quality of life } \\
\hline High (score $>5$ ) & 5,214 & 15.5 & $1.00^{\wedge}$ & 4,406 & 1.1 & $1.00^{\wedge}$ & 808 & 17.6 & $1.00^{\wedge}$ \\
\hline Low $($ score $\leq 5)$ & 789 & 21.9 & $1.61(1.33-1.95)$ & 616 & 0.9 & $0.85(0.36-2.04)$ & 172 & 29.7 & $1.97(1.34-2.88)$ \\
\hline \multicolumn{10}{|l|}{ Sleep quantity } \\
\hline High ( $\geq 7$ h/night $)$ & 3,983 & 15.7 & $1.00^{\wedge}$ & 3,358 & 1.0 & $1.00^{\wedge}$ & 625 & 15.6 & $1.00^{\wedge}$ \\
\hline Low $(<7 \mathrm{~h} /$ night $)$ & 2020 & 17.6 & $1.12(0.97-1.30)$ & 1,664 & 1.4 & $1.54(0.90-2.65)$ & 356 & 27.0 & $2.00(1.45-2.77)$ \\
\hline \multicolumn{10}{|l|}{ Sleep quality } \\
\hline Good/Quite good & 4,985 & 15.7 & $1.00^{\wedge}$ & 4,202 & 1.2 & $1.00^{\wedge}$ & 783 & 18.5 & $1.00^{\wedge}$ \\
\hline Bad/Quite bad & 1,018 & 19.4 & $1.32(1.11-1.58)$ & 821 & 0.9 & $0.80(0.37-1.73)$ & 198 & 24.4 & $1.36(0.93-1.99)$ \\
\hline \multicolumn{10}{|l|}{ Depressive symptoms (PHQ-2) } \\
\hline No $($ score $<3)$ & 5,143 & 15.2 & $1.00^{\wedge}$ & 4,363 & 1.1 & $1.00^{\wedge}$ & 780 & 15.5 & $1.00^{\wedge}$ \\
\hline Yes (score $\geq 3$ ) & 860 & 23.3 & $1.82(1.52-2.18)$ & 660 & 1.4 & $1.37(0.67-2.79)$ & 201 & 35.9 & $3.06(2.13-4.39)$ \\
\hline \multicolumn{10}{|l|}{ Anxiety symptoms (GAD-2) } \\
\hline No $($ score $<3$ ) & 4,915 & 14.9 & $1.00^{\wedge}$ & 4,183 & 1.1 & $1.00^{\wedge}$ & 731 & 14.8 & $1.00^{\wedge}$ \\
\hline Yes (score $\geq 3$ ) & 1,088 & 22.9 & $1.87(1.58-2.22)$ & 839 & 1.3 & $1.21(0.62-2.37)$ & 249 & 34.0 & $2.93(2.08-4.13)$ \\
\hline
\end{tabular}

${ }^{\circ}$ Estimated by unconditional multiple logistic regression models after adjustment for sex, age, education level and geographic area; estimates in bold are those statistically significant at 0.05 level.

$\wedge$ Reference category.

Persons with behavioral addictions experienced greater reactivity to environmental cues compared to the general population (Starcke, Antons, Trotzke, \& Brand, 2018). Those subjects trigger conditioned emotional reactions and provide the basis for explaining the variations in craving and the strength of the withdrawal syndrome with varying environmental exposure. The use of a substance or a behavior leads to the desired effect, thus determining an operative conditioning which leads to increase the use (Drummond, 2001). Conversely, a reduction in stimuli leads to a reduction in craving and addictive behavior. For this reason, we considered the possibility that the reduction of traditional gambling due to the lockdown reduced the incentives, consequently decreasing the craving for pathological gambling.

Despite some specific types of traditional gambling games were banned during COVID-19 lockdown, the nonzero prevalence of use of such games during lockdown might reveal a misclassification of games among participants and/ or could suggest that a non-negligible portion of subjects have been involved in some forms of informal or illegal land-based gambling during lockdown. A less marked decrease in the online gambling prevalence from prior to during lockdown can be justified by confinement at home and social distancing. Confinement indeed have induced people to increase their interaction and activities online, including, possibly, playing gambling. Moreover, some other subjects who used to play traditional gambling in pre-lockdown might have decided to switch to online gambling during stay-at-home orders.

Few studies so far have analyzed the effects of COVID-19 lockdown on gambling habits. A cross-sectional online study conducted on 2016 subjects from the general adult population in Sweden within the same time frame of our study showed that, in line with our study, a small proportion of study participants (i.e., $4 \%$ ) reported an increase in gambling activity and that the worsening group was characterized by severe gambling addiction (Hakansson, 2020). It is although worth to mention that in Sweden there was no lockdown due to COVID-19 pandemic, therefore a comparison with the results of our study on the Italian population are to be considered with caution. Another online survey was conducted between late March and mid May 2020 on 764 Australian adults, predominantly males and former gamblers, with the aim of investigating the impact of COVID-19 lockdown on their gambling behavior. Preliminary results showed that approximately $11 \%$ of study participants increased their gambling activity during lockdown (The University of Sidney, 2020).

In our study, gambling behaviors before the lockdown were associated with being young and male. These results 
Table 4. Distribution of 980 Italian baseline gamblers (before the COVID-19 lockdown) according to an improvement in total gambling activity (i.e., reduce or stop playing) during COVID-19 lockdown, overall and by socio-demographic characteristics. Corresponding odds ratios $^{\circ}(\mathrm{OR})$ and $95 \%$ confidence intervals (CI). Italy, 2020

\begin{tabular}{|c|c|c|c|c|c|}
\hline \multirow[b]{3}{*}{ Characteristics before lockdown } & \multicolumn{5}{|c|}{ Gambling players at baseline } \\
\hline & \multirow[b]{2}{*}{$N$} & \multicolumn{2}{|c|}{$\begin{array}{l}\text { Stopping playing during } \\
\text { lockdown }\end{array}$} & \multicolumn{2}{|c|}{$\begin{array}{l}\text { Reducing playing during } \\
\text { lockdown }\end{array}$} \\
\hline & & $\%$ & OR $(95 \% \mathrm{CI})$ & $\%$ & OR $(95 \% \mathrm{CI})$ \\
\hline Total & 980 & 46.2 & & 25.5 & \\
\hline \multicolumn{6}{|l|}{ Sex } \\
\hline Women & 303 & 49.1 & $1^{\wedge}$ & 23.8 & $1^{\wedge}$ \\
\hline Men & 677 & 45.0 & $1.05(0.75-1.46)$ & 26.2 & $0.93(0.63-1.36)$ \\
\hline \multicolumn{6}{|l|}{ Age group } \\
\hline $18-34$ & 314 & 39.6 & $1^{\wedge}$ & 26.9 & $1^{\wedge}$ \\
\hline $35-54$ & 427 & 47.5 & $1.43(1.01-2.02)$ & 25.0 & $1.15(0.78-1.71)$ \\
\hline $55-74$ & 239 & 52.7 & $1.99(1.31-3.02)$ & 24.5 & $1.37(0.85-2.21)$ \\
\hline$P$ for trend & & & 0.001 & & 0.194 \\
\hline \multicolumn{6}{|l|}{ Level of education } \\
\hline Low & 146 & 42.8 & $1^{\wedge}$ & 32.2 & $1^{\wedge}$ \\
\hline Intermediate & 494 & 47.3 & $1.00(0.63-1.60)$ & 25.0 & $0.69(0.42-1.15)$ \\
\hline High & 341 & 46.2 & $0.92(0.56-1.50)$ & 23.3 & $0.60(0.35-1.03)$ \\
\hline P for trend & & & 0.643 & & 0.074 \\
\hline \multicolumn{6}{|l|}{ Geographic area } \\
\hline Northern Italy & 411 & 47.5 & $1^{\wedge}$ & 25.7 & $1^{\wedge}$ \\
\hline Central Italy & 205 & 40.3 & $0.60(0.41-0.89)$ & 22.6 & $0.65(0.41-1.02)$ \\
\hline Southern Italy \& Islands & 365 & 48.2 & $1.10(0.78-1.56)$ & 26.9 & $1.19(0.80-1.76)$ \\
\hline
\end{tabular}

${ }^{\circ}$ Estimated by unconditional multiple logistic regression models after adjustment for sex, age, education level and geographic area; estimates in bold are those statistically significant at 0.05 level.

$\wedge$ Reference category.

are in line with a recent literature review on gambling disorder (Potenza et al., 2019), and with a study conducted in Italy on a representative sample of 4,773 adults aged from 18 to 94 years (Cavalera et al., 2018).

In our study we observed that worsening in gambling behavior, either by starting or increasing intensity of gambling, was associated with young age. This can be explained with the prolonged period of isolation that might have induced young people to consider online gambling as a valid recreational activity at home. Similarly, the Swedish web survey has identified that being a young man and spending more time at home were associated with an increase in gambling activity (Hakansson, 2020).

We observed that survey participants having or having had an addiction were more likely to both play gambling before lockdown and worsen gambling activity during the lockdown. In line with current available literature, being a smoker (Latvala et al., 2019; Pacifici et al., 2019), or a cannabis user (Pacifici et al., 2019; Xian, Giddens, Scherrer, Eisen, \& Potenza, 2014), or being affected by alcohol use disorder (Pacifici et al., 2019; Potenza et al., 2019), were all associated with being a gambler before lockdown. We also observed that electronic cigarette and HTP use were associated with being a gambler before lockdown. The addictive behaviors mentioned above were also associated with increasing the intensity of gambling during lockdown. It is particularly interesting to point out that cannabis was the only addictive behavior associated with starting gambling during the confinement period.

In line with available literature, we found a significant relationship between several mental health symptoms and being a gambler before COVID-19 lockdown, including consuming psychotropic drugs (Potenza et al., 2019), reporting a low quality of life (Bonfils et al., 2019), low sleep quality (Parhami et al., 2012), depressive symptoms (Potenza, Xian, Shah, Scherrer, \& Eisen, 2005; Quigley et al., 2015) and anxiety symptoms (Bonfils et al., 2019). The same mental health indicators were also associated with increasing gambling activity during lockdown. Moreover, the use of psychotropic drugs before lockdown was also related with starting gambling during lockdown.

The study presents some limitations worth to mention. Firstly, results were obtained via a web-survey. This mode of data collection intrinsically introduces a selection bias towards a portion of population actively using internet, excluding therefore less wealthy subgroups of the population who do not have access to internet or use it less frequently. However, our sample had a distribution by socio-economic characteristics, including income and level of education, similar to those of the general Italian population. Moreover, a web-survey was the best option to reach subjects during the lockdown, given the restrictions in place. Secondly, a response-shift bias might also have affected information provided by the subjects in relation to before and during lockdown. In fact, reported changes in habits within this 
time frame might reflect individual perceptions of the change, more than real changes in behaviors due to the lockdown. Thirdly, answers provided by study participants on selected topics might have also been affected by the seasonal effect with respect to before (winter season) and during lockdown (spring season). Another limitation worth to mention, is the definition of gambler used, that, even if in accordance with previous literature (Pacifici et al., 2019) does not allow to distinguish occasional gamblers from heavy gamblers. However, in a sensitivity analysis, the changes in prevalence for heavy players were consistent with those for any players. Another limitation is related to mental health indicators: the PHQ-2 and GAD-2 scales used to assess depression and anxiety only represent a first step screening and not a clinical evaluation. However, this was not among the aims of the present survey and the length of the questionnaire did not allow any deeper investigation. More importantly, we did not have the possibility to use a probability sampling methodology which would have better ensured the representativeness of the target population. Finally, as this is a cross-sectional study, it is not possible to establish any causal relationship, although all efforts have been considered to give a longitudinal context to the analyses. Thus, all the possible determinants of changes in gambling habit, including addictive behaviors, referred to a time frame prior the lockdown.

Despite these limitations, to our knowledge this is the first study aimed at analyzing the effect of COVID-19 lockdown on gambling habits on a national representative sample of the adult population. In addition, it is also worth to mention that data were collected in the last weeks of a two month-long home confinement. The section of questions focused on gambling habits during lockdown refers to the same specific time frame nested within the most restrictive period of lockdown ensuring data uniformity and minimizing therefore memory and recall biases.

The COVID-19 pandemic and its response had and will have consequences on all levels of our society, including its psychological wellbeing (Holmes et al., 2020). Although our results show that gambling activity has definitely decreased during lockdown, time spent in gambling has slightly increased. As described in previous studies, increased time spent gambling might be an indicator of the development of gambling disorders (Fong, 2005). It will be relevant therefore to monitor gambling consumption levels in the post lockdown period. Specifically, it would be useful to identify additional indicators which could be easily tracked over time in order to define strategies to support the most vulnerable population and the new potential subjects addicted to gambling. This goal can only be achieved through a transdisciplinary approach which involves epidemiologists, public health researchers and practitioners, mental health experts and policy makers (Lopez-Pelayo et al., 2020). In addition, it is particularly important to consider the well known, here confirmed, strong relationship between mental health and addictive behaviors with gambling. Gambling is highly comorbid with other psychiatric disorders. In this critical period of uncertainty and psychological disorientation, new policies should be adopted to monitor and prevent these mentally vulnerable subgroups of the population from increasing and developing gambling disorders.

Funding sources: The project was carried out with the technical and financial support of the Italian Ministry of Health - CCM. The survey was co-funded by Fondazione Cariplo. The work of SG, AL, CS and AO is partially supported by a research grant of the DG-Welfare of Lombardy Region (Call: Progetti di ricerca in ambito sanitario connessi all'emergenza COVID 19; DGR n. XI/3017) and by a grant of the AXA (AXA Research Fund - Call for Proposals Covid-19). The work of GG is partially supported by the Tuscany Region within the Lost in Toscana Project.

Authors' contribution: RP and SG conceptualized and designed the study. RP and AO obtained funding. AL, CS, and LP analyzed the data under the supervision of SG. SG, AL, CS, and LP wrote the first draft of the manuscript. AA, GG, LM, AM, CM, AO, RP, GC and BT provided important contributions for the interpretation of findings. RP, AO, and SG provided supervision and important intellectual supports in various steps of the study All authors carefully revised the final version of the manuscript. All authors have read and approved the last version of the manuscript.

Conflict of interests: The authors declare no conflict of interest.

\section{SUPPLEMENTARY MATERIAL}

Supplementary data to this article can be found online at https://doi.org/10.1556/2006.2021.00033.

\section{REFERENCES}

Agenzie Dogane Monopoli. (2020). Prot.: 180229/RU - Determinazione direttoriale. Avaliable at: https://www.adm.gov.it/ portale/documents/20182/5799244/Determinazione+Riaper turaRev.pdf/c09e72d8-5d0a-418d-81f3-8915bad7ac2a [Accessed: 03/12/2020].

Australian Institute of Criminology. (2020). Changes in online gambling during the COVID-19 pandemic. Avaliable at: https://apo.org.au/sites/default/files/resource-files/2020-05/aponid303649.pdf [Accessed: 12/10/2020].

Bogart, W. A. (2011). Permit But Discourage: Regulating Excessive Consumption. New York: Oxford University Press, Inc.

Bonfils, N. A., Grall-Bronnec, M., Caillon, J., Limosin, F., Benyamina, A., Aubin, H. J., et al. (2019). Giving room to subjectivity in understanding and assessing problem gambling: A patient-centered approach focused on quality of life. Journal of Behavioral Addictions, 8(1), 103-113. https://doi.org/10.1556/2006.7.2018.137.

Buysse, D. J., Reynolds, C. F., 3rd, Monk, T. H., Berman, S. R., \& Kupfer, D. J. (1989). The Pittsburgh sleep quality index: A new 
instrument for psychiatric practice and research. Psychiatry Research, 28(2), 193-213. https://doi.org/0165-1781(89)900474 [pii] 10.1016/0165-1781(89)90047-4.

Calado, F., \& Griffiths, M. D. (2016). Problem gambling worldwide: An update and systematic review of empirical research (20002015). Journal of Behavioral Addictions, 5(4), 592-613. https:// doi.org/10.1556/2006.5.2016.073.

Carreras, G., Lugo, A., Stival, C., Amerio, A., Odone, A., Pacifici, R., et al. (2021). COVID-19 lockdown impact on smoking consumption in a large representative sample of Italian adults. Tobacco Control, in press. https://doi.org/10.1136/ tobaccocontrol-2020-056440.

Cavalera, C., Bastiani, L., Gusmeroli, P., Fiocchi, A., Pagnini, F., Molinari, E., et al. (2018). Italian adult gambling behavior: At risk and problem gambler profiles. Journal of Gambling Studies, 34(3), 647-657. https://doi.org/10.1007/s10899-017-9729-8.

Drummond, D. C. (2001). Theories of drug craving, ancient and modern. Addiction, 96(1), 33-46. https://doi.org/10.1046/j. 1360-0443.2001.961333.x.

Elton-Marshall, T., Leatherdale, S. T., \& Turner, N. E. (2016). An examination of internet and land-based gambling among adolescents in three Canadian provinces: Results from the youth gambling survey (YGS). BMC Public Health, 16, 277. https:// doi.org/10.1186/s12889-016-2933-0.

Fong, T. W. (2005). The biopsychosocial consequences of pathological gambling. Psychiatry (Edgmont), 2(3), 22-30.

Hakansson, A. (2020). Changes in gambling behavior during the COVID-19 pandemic-A web survey study in Sweden. International Journal of Environmental Research and Public Health, 17(11). https://doi.org/ijerph17114013 [pii].

Holmes, E. A., O'Connor, R. C., Perry, V. H., Tracey, I., Wessely, S., Arseneault, L., et al. (2020). Multidisciplinary research priorities for the COVID-19 pandemic: A call for action for mental health science. Lancet Psychiatry, 7(6), 547-560. https://doi.org/ S2215-0366(20)30168-1 [pii].

King, D. L., Delfabbro, P. H., Billieux, J., \& Potenza, M. N. (2020). Problematic online gaming and the COVID-19 pandemic. Journal of Behavioral Addictions, 9(2), 184-186. https://doi.org/ 10.1556/2006.2020.00016.

Kroenke, K., Spitzer, R. L., \& Williams, J. B. (2003). The patient health questionnaire-2: Validity of a two-item depression screener. Medical Care, 41(11), 1284-1292. https://doi.org/10. 1097/01.MLR.0000093487.78664.3C.

Latvala, T., Lintonen, T., \& Konu, A. (2019). Public health effects of gambling - debate on a conceptual model. BMC Public Health, 19(1), 1077. https://doi.org/10.1186/s12889-019-7391-z.

Lopez-Pelayo, H., Aubin, H. J., Drummond, C., Dom, G., Pascual, F., Rehm, J., et al. (2020). "The post-COVID era”: Challenges in the treatment of substance use disorder (SUD) after the pandemic. BMC Medicine, 18(1), 241. https://doi.org/10.1186/ s12916-020-01693-9.

Mallet, J., Dubertret, C., \& Le Strat, Y. (2020). Addictions in the COVID-19 era: Current evidence, future perspectives a comprehensive review. Progress In Neuro-Psychopharmacology \& Biological Psychiatry, 110070. https://doi.org/S0278-5846(20)30386-9 [pii].

Odone, A., Lugo, A., Amerio, A., Borroni, E., Bosetti, C., Carreras, G., et al. (2020). COVID-19 lockdown impact on lifestyle habits of Italian adults. Acta BioMedica, 91(9-S), 87-89. https://doi.org/10.23750/abm.v91i9-S.10122.

Pacifici, R., Mastrobattista, L., Minutillo, A., \& Mortali, C. (2019). "Gioco d'azzardo in Italia: ricerca, formazione e informazione": risultati di un progetto integrato. Roma: Istituto Superiore di Sanità; 2019. (Rapporti ISTISAN 19/28). Available online at: /www.iss.it/documents/20126/0/19-28+web.pdf/20ad90e2-3339f919-41fe-fd62c2ec7464? $\mathrm{t}=1586527475379$ [Accessed: 11/01/ 2021].

Parhami, I., Siani, A., Rosenthal, R. J., Lin, S., Collard, M., \& Fong, T. W. (2012). Sleep and gambling severity in a community sample of gamblers. Journal of Addictive Diseases, 31(1), 67-79. https://doi.org/10.1080/10550887.2011.642754.

Potenza, M. N., Balodis, I. M., Derevensky, J., Grant, J. E., Petry, N. M., Verdejo-Garcia, A., et al. (2019). Gambling disorder. Nature Reviews Disease Primers, 5(1), 51. https://doi.org/10.1038/ s41572-019-0099-7.

Potenza, M. N., Kosten, T. R., \& Rounsaville, B. J. (2001). Pathological gambling. Journal of the American Medical Association, 286(2), 141-144. https://doi.org/jct10004 [pii] 10.1001/jama.286.2.141.

Potenza, M. N., Xian, H., Shah, K., Scherrer, J. F., \& Eisen, S. A. (2005). Shared genetic contributions to pathological gambling and major depression in men. Archives of General Psychiatry, 62(9), 1015-1021. https://doi.org/10.1001/archpsyc.62.9.1015.

Presidenza del Consiglio dei Ministri. (2020). Dpcm 9 March 2020 Avaliable at: http://www.governo.it/it/articolo/firmato-il-dpcm9-marzo-2020/14276\# [Accessed:12/10/2020].

Quigley, L., Yakovenko, I., Hodgins, D. C., Dobson, K. S., ElGuebaly, N., Casey, D. M., et al. (2015). Comorbid problem gambling and major depression in a community sample. Journal of Gambling Studies, 31(4), 1135-1152. https://doi.org/ 10.1007/s10899-014-9488-8.

Robinson, A., Loomes, G., \& Jones-Lee, M. (2001). Visual analog scales, standard gambles, and relative risk aversion. Medical Decision Making, 21(1), 17-27. https://doi.org/10.1177/ 0272989X0102100103.

Saglietto, A., D'Ascenzo, F., Zoccai, G. B., \& De Ferrari, G. M. (2020). COVID-19 in Europe: The Italian lesson. Lancet, 395(10230), 1110-1111. https://doi.org/S0140-6736(20)30690-5 [pii].

Saunders, J. B., Aasland, O. G., Babor, T. F., de la Fuente, J. R., \& Grant, M. (1993). Development of the alcohol use disorders identification test (AUDIT): WHO collaborative project on early detection of persons with harmful alcohol consumptionII. Addiction, 88(6), 791-804. https://doi.org/10.1111/j.13600443.1993.tb02093.x.

Signorelli, C., Scognamiglio, T., \& Odone, A. (2020). COVID-19 in Italy: Impact of containment measures and prevalence estimates of infection in the general population. Acta BioMedica, 91(3-S), 175-179. https://doi.org/10.23750/abm.v91i3-S.9511.

Spitzer, R. L., Kroenke, K., \& Williams, J. B. (1999). Validation and utility of a self-report version of PRIME-MD: The PHQ primary care study. Primary care evaluation of mental disorders. Patient health questionnaire. Journal of the American Medical Association, 282(18), 1737-1744. https://doi.org/10.1001/jama.282.18.1737.

Starcke, K., Antons, S., Trotzke, P., \& Brand, M. (2018). Cuereactivity in behavioral addictions: A meta-analysis and methodological considerations. Journal of Behavioral Addictions, 7(2), 227-238. https://doi.org/10.1556/2006.7.2018.39. 
The data team, (2017). The world's biggest gamblers, The Economist. 9 February 2017. Retrieved from http://www.economist. com/blogs/graphicdetail/2017/02/daily-chart-4.

The University of Sidney. (2020). The impact of the COVID-19 shutdown on gambling in Australia. Preliminary results from Wave 1 cross-sectional survey. Avaliable at: https://www. sydney.edu.au/content/dam/corporate/documents/brain-andmind-centre/usyd-covid-gambling-research-report-aug-2020. pdf [Accessed 12/10/2020].

World Health Organization. (2017). The epidemiology and impact of gambling disorder and other gamblingrelated harm. Avaliable at: https://www.who.int/docs/ default-source/substance-use/the-epidemiology-and-impactof-gambling-disorder-and-other-gambling-relate-harm. pdf?sfvrsn $=5901$ c849_2\&download $=$ true [Accessed 12/10/ 2020].

Xian, H., Giddens, J. L., Scherrer, J. F., Eisen, S. A., \& Potenza, M. N. (2014). Environmental factors selectively impact co-occurrence of problem/pathological gambling with specific drug-use disorders in male twins. Addiction, 109(4), 635-644. https://doi. org/10.1111/add.12407.

Yahya, A. S., \& Khawaja, S. (2020). Problem gambling during the COVID-19 pandemic. Prim Care Companion CNS Disord, 22(4). https://doi.org/10.4088/PCC.20com02690. 